Charnock, David. (2003). Institutionally-induced pendulum? An assessment of state-level influences on postwar Australian federal voting, Australian Journal of Political Science, 38(1):119-132.

\title{
Institutionally-induced pendulum? An assessment of state-level influences on postwar Australian federal voting
}

\section{David Charnock}

School of Social Sciences,

Curtin University

GPO Box U1987,

Perth WA 6845,

Australia.

Email: D.M.Charnock@curtin.edu.au 
Charnock, David. (2003). Institutionally-induced pendulum? An assessment of state-level influences on postwar Australian federal voting, Australian Journal of Political Science, 38(1):119-132.

\title{
Institutionally-induced pendulum? An assessment of state-level influences on postwar Australian federal voting
}

\begin{abstract}
The extent of state-level influences on federal voting behaviour in Australia has been debated for many years. In this paper, I extend and improve on previous research by using the most advanced techniques (multilevel modelling) available for analysing survey data in this context, and present results based on an extensive investigation of postwar Australian elections.

The results conclusively show that the overall extent of measurable state-level effects on federal voting over the period is relatively very small, despite the institutional significance of the states. In an attempt to reconcile these two facts, I therefore propose an institutional explanation of the small extent of state-level effects. I argue that the representation entitlements of the states in the House of Representatives would tend to result in the overall extent of state-level effects being relatively small because they introduce a self-correcting, 'pendulum' element into party competition. I investigate some hypotheses that follow from this argument, demonstrate that the evidence from the multilevel modelling is consistent with these hypotheses and conclude that this institutional element is a significant part of the explanation of the apparent unimportance of state-level influences.
\end{abstract}


Charnock, David. (2003). Institutionally-induced pendulum? An assessment of state-level influences on postwar Australian federal voting, Australian Journal of Political Science, 38(1):119-132.

\section{Institutionally-induced pendulum? An assessment of state-level influences on postwar Australian federal voting}

\section{Introduction}

Given the natural interest in the working of Australian federalism, it is only to be expected that the extent and nature of state-level influences on voting in Australian federal elections are topics that have been addressed many times, and over a lengthy period. Some significant early instances (based on one or both of aggregate voting data and individual survey data) of detailed attempts to explore the topics are included in Alford (1963), Aitkin (1977), Austen (1977), Holmes and Sharman (1977) and Kemp (1978).

There was a rather extensive debate during the 1970s and early 1980s that was often framed in terms of the existence (or not) of uniform swings. The theme was revisited after the 1990 federal election by Bean and Butler (1991a; 1991b) and Sharman (1991), and these authors also summarise the main features of the earlier debates. The extent and causes of regional differences in voting have also been examined in a number of other countries, with a particularly vigorous debate in Britain (e.g. McAllister and Studlar 1992; Johnston 1987; McAllister 1987).

Although not many of the Australian authors argued that state variations were large ${ }^{1}$, and Kemp $(1978,257)$ used a variance components method to conclude that '...there had indeed been an increasing nationalization of mass political responses in Australia from 1940 to 1972, with a declining proportion of variance attributable to state and local factors', others (e.g. Holmes and Sharman) noted that regional variations do occur and might be important because of the small margins generally present in Australian elections.

Possible explanations for state variations that could be (and have been) explored include the existence of regional political cultures (sometimes on the basis of being a residual consequence of the fact that the states originally were independent colonies), having differing economic interests, industrial bases or social compositions, and institutional ones that derive from the role of the states in the national federation. 
Charnock, David. (2003). Institutionally-induced pendulum? An assessment of state-level influences on postwar Australian federal voting, Australian Journal of Political Science, 38(1):119-132.

On this last point, it is a recurring theme of journalists and commentators that the popularity (or unpopularity) of state governments and politicians also have an impact on federal voting behaviour in the same state. Although not argued as frequently, it is also possible that on occasions the impact works in the reverse direction, with the standing of federal leaders and governments having an influence on voting at state elections. Sharman and Sayers (1998) use aggregate voting data to show that there are differences in levels of voting for the ALP at state and federal elections, which demonstrates that (at least some) voters do differentiate between the two spheres, but did not have data available that would allow them to explore various possible explanations for this finding.

The primary basis for believing in possible direct connections between state and federal voting behaviour is, of course, the fact that the same political parties contest both federal and state elections. The fact that the organisational structures of the main national parties are federal ones is another obvious consideration, despite the existence of some variations in the strength of this between parties and also some changes over time. In a similar vein, despite his general emphasis on other explanations for the increasing nationalization he found, Kemp also suggests a significant mediating role for the major parties and argues that they are 'important integrating institutions' (Kemp 1978, 257) ${ }^{2}$.

Building on the contributions made by the earlier research, during the 1990s the topic of state-level effects on federal voting was investigated in Australia with more conceptual and methodological sophistication. In terms of examining possible causes of state-level variations in federal voting, Denemark and Sharman (1994) used survey data to investigate differences in state political cultures and found few evident in 1993. They did, however, identify some differences in attitudes towards trust in federal and state governments that might have an impact in some circumstances. It was demonstrated in Charnock (1994) that there was an extremely large amount of residential mobility between elections (in Western Australia, an average turnover at divisional level of about 30\% over a three year period). This makes drawing conclusions about changes in individual voting behaviour from aggregate voting swings in electoral divisions extremely problematic and subsequent work (Charnock 
Charnock, David. (2003). Institutionally-induced pendulum? An assessment of state-level influences on postwar Australian federal voting, Australian Journal of Political Science, 38(1):119-132.

1996; 1997) applied the quite recently developed technique of multilevel analysis to individual survey data. This technique allows for the simultaneous measurement of the extent of influences at different spatial levels (including the state level), after controlling for individual social characteristics if desired. Among other things, use of this new method demonstrated that the extent of state-level effects was relatively small at both the 1993 and 1996 elections, with divisional-level effects being much more significant (though smaller than equivalent ones in Britain).

Returning to the analysis of aggregate voting data, Leithner (1997) made use of an improved version of the technique used earlier by Kemp to produce an extended analysis for the period from 1900-88. His analyses too demonstrated that components attributable to divisional-level variations were consistently much larger than statelevel ones. He linked this to relatively low levels of partisan dealignment in Australia and contrasted this with the situation in the USA, where he says that partisan dealignment has led to an emphasis on individual candidates and local issues. However, while levels of partisan dealignment in Australia are not as high as in the USA, there is still evidence of weakening in party identification since the late 1970s (see McAllister 1997, 251, for example). Therefore, if Leithner's argument is correct (and it does seem plausible) then we might expect to see some impact on the extent of state-level influences in this period. If we do not find these, then we would need to search for alternative explanations.

To investigate the topic comprehensively, examinations of both aggregate and survey data are needed, because they can fulfil complementary roles. By their nature (being based on aggregate voting data), Leithner's conclusions suffer from the disadvantage that they cannot disaggregate down to the level of individual voters and are always potentially subject to difficulties resulting from differences in the social composition of electoral divisions ${ }^{3}$. By being able to incorporate individual-level influences as well as the aggregated-level ones (divisional and state) dealt with in Leithner's research, multilevel analyses of survey data for an extended period would help to finally complete the picture that has been developed during this very lengthy debate. 
Charnock, David. (2003). Institutionally-induced pendulum? An assessment of state-level influences on postwar Australian federal voting, Australian Journal of Political Science, 38(1):119-132.

One of the main purposes of this article, therefore, is to apply this advanced analytical method to the full postwar period, in order to provide a more reliable assessment of how the relative extent of state-level influences on Australian federal voting varied during the second half of the twentieth century. Although almost all previous research in the area has analysed voting for the House of Representatives, one could possibly also make a case for examining Senate voting. However, the survey data necessary for such a study are not available for this complete period and so I deal only with voting at elections for the House of Representatives.

As argued earlier by Holmes and Sharman (1977), even if state-level effects on federal voting are relatively small, they are nevertheless potentially significant because of the fact that margins in Australian elections are generally small. Furthermore, the federal structures of the main political parties necessarily make the state an important unit of analysis. Consequently, in addition to assessing the overall relative extent of state-level effects, some further exploration of explanations for these effects is desirable.

One of the most commonly mentioned of these is that state-level influences result (at least partially) from responses to state governments and political leaders. However, since Australian surveys seldom ask direct questions about assessments of state governments and politicians, it is not possible to address this aspect directly for the postwar period. What is possible, however, is to examine whether state-level effects are still apparent after controlling for socio-demographic characteristics (since differences in social composition between states would be the other major source of inter-state variations in voting). Although the effects that remain after controlling for socio-demographic features would not completely be attributable to the influence of state governments, they would give us a good indication of what the maximum size of this influence on federal voting might be.

Investigating these sort of state-level effects can also be done within a multilevel modelling framework and I will also do this in some detail in this article.

\section{An institutional explanation: some hypotheses}

In addressing the first of these questions (about the relative extent of state-level effects), it is the overall balance between various spatial levels that is being examined 
Charnock, David. (2003). Institutionally-induced pendulum? An assessment of state-level influences on postwar Australian federal voting, Australian Journal of Political Science, 38(1):119-132.

and so, while it is possible to identify the contributions of individual states to the state-level variation, this is not always necessary. However, in the case of the second question (about the impact of state leaders and governments), it is essential to identify states separately, since it is responses in particular states that are postulated as having some impact.

Because of this difference between the two questions, it will often be useful to adopt a way of thinking about the factors that might have an impact on state effects that is framed in institutional terms. This will also help in testing explanations of why statelevel effects are relatively small (if this is confirmed to be the case). In particular, I wish to consider the impact of one crucial aspect of the electoral system viz. the nature of the representation of the states in the House of Representatives. At least five of the six states (Tasmania to a lesser degree) have a large enough number of seats in the House to have a reasonable chance of being significant in determining which party wins government ${ }^{4}$. This is unlike the situation in the USA, with which comparisons of the extent of state-level effects have been made by both Kemp and Leithner. There, the state with the highest representation (and this by quite a large margin) in the US House of Representatives is California. However, even California has only about the same proportion of seats (around 10\%) as does Western Australia (which is only the fourth most populous of the Australian states). Even looking at the position of Tasmania (which has easily the lowest representation of any of the Australian states), its relative representation is exceeded by fewer than 10 of the 50 states in the USA.

An immediate consequence is that the main political parties in Australia simply cannot afford to let divergences in voting behaviour between states become large, and the consideration of state representation entitlements must inevitably be of major concern to any party wishing to form government. I argue that it combines with the flexibility resulting from the federal structures of the main parties to introduce a selfcorrecting (or 'pendulum') element into electoral competition because no major party can afford to suffer a consistently large deficit in any state and so will be obliged to act to avoid this situation arising. 
Charnock, David. (2003). Institutionally-induced pendulum? An assessment of state-level influences on postwar Australian federal voting, Australian Journal of Political Science, 38(1):119-132.

Several consequences should follow from this observation and I offer the following hypotheses about what the postwar multilevel analyses would show if it were correct:

1. With the possible exception of isolated instances of short-term impacts, the overall extent of state-level effects would show no consistent changes over the period, because the main parties could not let this happen. Moreover,

2. The relative importance of state-level effects will be uniformly small during the period, possibly except at times of crisis in the party system, when party adaptation may be in train.

3. Any state-level effects that are present are more likely to be in less populous states, because their smaller representation entitlements mean they are less significant for winning government.

\section{Methods of analysis and data}

As outlined in Jones et al. (1992), for example, multilevel models have a number of advantages over single level ones when appropriate data are available, including that of being able to identify the extent of variations in voting at different spatial levels. However, because of the limited nature of the geographic identifiers available in many of the survey data sets for the early part of the postwar period, the most detailed multilevel modelling that is generally possible in the Australian context (incorporating electoral divisions as well as states) can only be carried out from 1966 onwards. It will therefore sometimes be necessary to use single-level models to ensure full direct comparability over the complete period. Where this has been necessary, I will also supplement the single-level results for the full postwar period by comparing the single- and multi-level results for the later period (1966 onwards) and noting the apparent consequences of using single-level models.

Analyses were mainly based on Gallup Polls (the only data source for the earliest part of the postwar period), though on occasions other sources such as the series of Australian Election Studies were used. Sample sizes were similar throughout (almost 
Charnock, David. (2003). Institutionally-induced pendulum? An assessment of state-level influences on postwar Australian federal voting, Australian Journal of Political Science, 38(1):119-132.

all in the range 1500 to 2000). Since minor parties such as the DLP, Australian

Democrats and One Nation have been present for only portions of the postwar period, to ensure comparability over the full period the logistic regressions are based on vote for the Australian Labor Party (ALP) in the House of Representatives and analyses reported here incorporated only ALP and Liberal-National coalition voters ${ }^{5}$ (though, where it was possible, I also made comparisons with results obtained if voters for these minor parties were also included, with no substantive differences to the results presented here).

\section{Results}

The first issue to be addressed is the overall extent of state-level effects over the period. It is important to note that this is the extent before any controls for aspects such as socio-demographic variations are applied. I will approach the measurement of this extent in two ways, first by using two-level models, with individuals as level one and states as level two, and second by using single-level models where the state effects are directly modelled as individual-level fixed effects, rather than as random effects. The first of these approaches to studying regional effects is the one adopted in the earliest applications of multilevel analysis to voting, both in Britain and Australia (Jones et al. 1992; Charnock 1996, respectively). The second formulation has been used more recently (e.g. Fisher 2000) and is more in accordance with the institutional effect approach that I outlined above in my hypotheses.

These earliest applications examined the extent of spatial variations by looking at the sizes of random effects at the various spatial levels but, to ensure comparability over time, results here are presented slightly differently, in terms of measures suggested by Snijders and Bosker (1999). In the case of measuring the proportion of variance attributable to state fixed effects, this is the multilevel equivalent of the most widelyused measure of explained variance in (single-level) logistic regression models ${ }^{6}$.

FIGURE 1 ABOUT HERE 
Charnock, David. (2003). Institutionally-induced pendulum? An assessment of state-level influences on postwar Australian federal voting, Australian Journal of Political Science, 38(1):119-132.

As Figure 1 clearly shows, the proportion of variance in voting for the ALP attributable to the state level in the two level models is uniformly trivial (mainly below 1\%). This certainly seems to support both Hypothesis 1 and Hypothesis 2. While it is possible to see minor fluctuations over time, the overall levels are so low that it would seem to be an over-interpretation to attach much significance to these variations.

Adopting the alternative approach, where state effects are modelled as fixed individual-level ones in single-level models (see Figure 2), makes no difference to the conclusion reached; the overall relative significance of state effects in explaining variations in ALP voting is uniformly small (again, mainly below 1\%).

\section{FIGURE 2 ABOUT HERE}

As explained earlier, Figure 2 is based on single-level models, since insufficient data on geographic information were available to use multilevel models with electoral divisions as one level (and individuals as the other) for the full postwar period. However, for the period from 1966 onwards the data do make this possible, still adopting the formulation of state effects as fixed individual-level ones. This alternative modelling strategy (which is, in principle, a superior one) does not, however, alter the conclusion in any way. The overall extent to which variations in voting for the ALP are explained by the state effects is almost identical to those shown in Figure 2; the details are not shown here because they are essentially indistinguishable from those in Figure 2.

As far as this aspect is concerned, therefore, the hypotheses that during the period there would be no consistent changes in the relative extent of observed state-level effects on voting for the ALP and that the extent of such effects would, in fact, be uniformly small are undoubtedly strongly supported. To put this relative extent into additional perspective, for the period from 1966 onwards (for which it was also possible to model effects at the level of electoral divisions), the proportion of variance 
Charnock, David. (2003). Institutionally-induced pendulum? An assessment of state-level influences on postwar Australian federal voting, Australian Journal of Political Science, 38(1):119-132.

attributable to the divisional level was, on average, about ten times as large as for the state level (around 8\%, compared to $0.8 \%$ ).

Variations attributable to the individual-level are, in turn, of considerably more relative significance than electoral division ones, and it is difficult to conclude anything other than that observed state-level effects on federal ALP voting are relatively of very minor significance. Of course, as noted earlier, this is not to argue that the states do not play an important institutional role. In fact, if my argument is correct, it is largely because of federal organisational structures and party adaptation at the state level that we observe such relatively minor state effects, and I now examine the institutional argument in more depth.

\section{Particular state effects}

It is the third hypothesis (about the presence of state effects being more likely to be observed in less populous states) that gives the strongest test of my argument about the impact of representation entitlements, because it gives a more detailed indication of where state effects should be found. However, in investigating this hypothesis for the complete postwar period I have, as explained earlier, had to use single-level modelling.

A priori, it is likely that the single-level models would exaggerate the extent of state effects. This is because, since the divisional level is omitted from the single-level models, it is probable that some portion of any divisional-level effects that are actually present will be incorrectly attributed to the state level. Therefore, in order to see whether the conclusions from the single-level modelling might need to be modified, I will also present comparable results for the post-1966 period based on two-level models (individuals and electoral divisions).

The results of the single-level modelling are shown in Table 1, which identifies which state effects were found to be statistically significant in the full postwar period. The underlying measure is whether being in a particular state increased or decreased the log-odds of voting for the ALP (vis-à-vis the Coalition) compared to being in New South Wales ${ }^{7}$, after individual social and economic factors are controlled for. As 
Charnock, David. (2003). Institutionally-induced pendulum? An assessment of state-level influences on postwar Australian federal voting, Australian Journal of Political Science, 38(1):119-132.

noted earlier, the controls for socio-demographic factors are applied in order to leave residual state effects that more closely approximate the impacts of state leaders and governments.

\section{TABLE 1 ABOUT HERE}

The table shows a total of 15 (statistically) significant state effects in the 22 elections that occurred during the period ${ }^{8}$. Although this is not a large number, it is greater than would be expected to have been found by chance because of sampling variations alone $^{9}$ and it is, therefore, safe to conclude that state effects are sometimes present, including after controlling for variations in social composition.

Of course, this does not tell us directly what the causes of these effects are, and I proceed to consider the specific suggestion in Hypothesis 3 that state effects are more likely to be present in the less populous states because of their smaller representation entitlements. Another technical aspect of statistical significance testing is relevant here, and means that there is more chance of correctly identifying effects in the more populous states ${ }^{10}$. Hence (see Note 4 ) the highest chance would be in Victoria, the next highest in Queensland and the smallest in Tasmania.

Bearing this in mind, the evidence in Table 1 clearly provides strong support for the hypothesis. Despite being the state for which effects are most likely to be correctly identified if present, only a single effect is found for Victoria ${ }^{11}$. At the other end of the scale of parliamentary representation, despite Tasmania being the state for which effects are least likely to be correctly identified, more significant effects (five) are identified for it than for any other state over the period as a whole.

The picture for the remaining states is not quite as clearcut, with the position of Western Australia being slightly anomalous. The position of Queensland from the mid-1970s to the mid-1980s also stands out somewhat. Nevertheless, even though the correspondence with relative levels of representation is not perfect, the overall tendency for state effects to be more likely to occur in less populous states is clear and I think Hypothesis 3 would undoubtedly be judged to be supported by this evidence ${ }^{12}$. 
Charnock, David. (2003). Institutionally-induced pendulum? An assessment of state-level influences on postwar Australian federal voting, Australian Journal of Political Science, 38(1):119-132.

However, as explained earlier, the single-level models are likely to over-estimate the extent of state effects because they do not incorporate divisional effects. As far as possible, therefore, it makes sense to make comparisons with results from two-level models that do incorporate the electoral division level separately, in order to avoid reaching inaccurate conclusions. Indeed, this is one of the reasons for using multilevel models in preference to the customary single-level ones.

\section{TABLE 2 ABOUT HERE}

Such two-level modelling can be done for the period from 1966. As expected, fewer significant effects are apparent: only eight significant effects are found in the resulting two level models (see Table 2), compared to 12 in the single level models for the same period. This confirms that the extent of state effects identified in the singlelevel modelling is an overstatement, but it is nevertheless true that eight significant effects is a larger number than would have been expected to have been found in the samples had there actually been no state effects present among the electorate as a whole ${ }^{13}$. So it is still reasonable to conclude that state effects were sometimes present, though certainly not often, nor even as often as indicated by the single-level models.

When the earlier comments about the relative power of tests in the various states are also taken into account, the evidence of Table 2 still provides quite strong support for Hypothesis 3: it shows a tendency for state effects to be more likely to be present in the less populous states. Tasmania has most and Victoria has fewest (none, in fact).

How many of these state effects that have been identified could reasonably be interpreted as being related (partially, at least) to the popularity or unpopularity of state governments or politicians? It is plausible that this is so for most of them, but there is no direct evidence for this in the surveys themselves, and there are many other instances where state governments were apparently equally popular (or unpopular) ${ }^{14}$ and yet no corresponding state effects have been found in these analyses. The number of statistically significant state effects that I have identified here is certainly far less than one would have imagined given the nature of commentary on the issue. 
Charnock, David. (2003). Institutionally-induced pendulum? An assessment of state-level influences on postwar Australian federal voting, Australian Journal of Political Science, 38(1):119-132.

\section{Conclusion}

The conclusions of this work can be divided into two parts, one being primarily descriptive and the other being an attempt to move towards an explanation of the descriptive findings. Descriptively, these analyses add to previous ones (by Leithner and other earlier authors) to complete the picture of observed state-level effects on federal voting for the ALP as being relatively very small and as having essentially been that way throughout the postwar period. Being able to be conclusive about this is important, since it means we can now focus on explaining why it is the case that statelevel effects are so small.

Since it is clear that the states play an important institutional role, I think it is appropriate to explore an institutionally-based explanation for the small size of statelevel effects. Following up on some of the implications of Kemp's and Leithner's suggestions that the role of the main political parties is significant, I have suggested that it is actually the flexibility introduced into Australian electoral politics by the federal structures of the main parties (combined with having quite similar social structures in the various states) that is responsible for the fact that observed state-level effects are relatively small.

The sizes of the parliamentary representation of the various states in the Australian House of Representatives are such that any party that allowed itself to suffer a consistently large deficit in any state (possibly excepting Tasmania) would find winning government difficult. Together with the flexibility of the party system, I argued that this introduces a self-correcting element at the state level into electoral competition in the House of Representatives. Support for this idea that representation entitlements are a primary driving force in keeping the size of state effects at a very low level comes from the multilevel analyses, which gave results that were generally quite consistent with three hypotheses that follow from this argument. Overall, therefore, while the states might help to structure the electoral competition at any particular election, the parties have successfully managed to avoid letting state differences become large or allowing differences to be maintained for anything more than quite short periods. 
Charnock, David. (2003). Institutionally-induced pendulum? An assessment of state-level influences on postwar Australian federal voting, Australian Journal of Political Science, 38(1):119-132.

In a comparative context, there is debate in the USA (e.g. Carsey and Wright 1998a; 1998b; Atkeson and Partin 1998) that examines both partisanship and state and national economic effects as influences on federal and state voting. However, I think the advantage of the institutionally-based argument is that it offers a simple and parsimonious explanation both for the 'pendulum' effect and also for the fact that observed state effects are so relatively small and insignificant compared to ones at either the divisional level or the individual level.

Also, without wishing to overstate its usefulness in understanding international comparisons, it is clearly the case that having few states, each with a reasonable degree of representation and relatively similar social and demographic structures, places different constraints on parties than would be there under other circumstances such as those in the USA.

Reactions to state governments and politicians are presumably among the constituent components that parties need to consider when responding to state-level impacts on federal voting, but other issues (such as differential impacts of national policies because of varying economic bases) would also come into play. I would suggest, however, that it is incumbent on proponents of the view that reactions to state governments play an important role in structuring federal voting to produce evidence to support this viewpoint and to assess its extent precisely, rather than merely assert the existence of the relationship ${ }^{15}$. 
Charnock, David. (2003). Institutionally-induced pendulum? An assessment of state-level influences on postwar Australian federal voting, Australian Journal of Political Science, 38(1):119-132.

\section{References}

Aitkin, D. 1977. Stability and Change in Australian Politics. Canberra: Australian National University Press.

Alford, R. 1963. Party and Society: The Anglo-American Democracies. Chicago: Rand McNally.

Atkeson, L.R. and R.W. Partin. 1998. 'Economic and Referendum Voting and the Problem of Data Choice: A Reply.' American Journal of Political Science 42:1003-7.

Austen, B. 1977. Uniformity and Variation in Australian Electoral Behaviour: State Voting Patterns in House of Representatives Elections 1946-1975. Occasional Monograph 1, Hobart: Department of Political Science, University of Tasmania.

Bean, C. 2002. 'Primus inter premiers: Or, The electoral influence of state party leaders.' Presented at the Annual National Conference of the Australasian Political Studies Association, The Australian National University, Canberra, October 2002.

Bean, C. and D. Butler. 1991a. 'Uniformity in Australian Electoral Patterns: The 1990 Federal Election in Perspective.' Australian Journal of Political Science 26:127-36.

Bean, C. and D. Butler. 1991b. 'Variability and Uniformity: A Response.' Australian Journal of Political Science 26:348-52.

Carsey, T.M. and G.C. Wright. 1998a. 'State and National Factors in Gubernatorial and Senatorial Elections.' American Journal of Political Science 42:994-1002.

Carsey, T.M. and G.C. Wright. 1998b. 'State and National Factors in Gubernatorial and Senatorial Elections: A Rejoinder.' American Journal of Political Science 42:1008-11.

Charnock, D. 1997. 'Spatial Variations, Contextual and Social Structural Influences on Voting for the ALP at the 1996 Federal Election: Conclusions from Multilevel Analyses.' Australian Journal of Political Science 32:237-54.

Charnock, D. 1996. 'National Uniformity, and State and Local Effects on Australian Voting: A Multilevel Approach.' Australian Journal of Political Science 31:51-65.

Charnock, D. 1994. 'Internal Migration and Elector Turnover in Australia.' Australian Journal of Political Science 29:292-301. 
Charnock, David. (2003). Institutionally-induced pendulum? An assessment of state-level influences on postwar Australian federal voting, Australian Journal of Political Science, 38(1):119-132.

DeMaris, A. 2001. 'Explained Variance in Logistic Regression: A Monte Carlo Study of Proposed Measures.' Presented at the Annual Meeting of the Southern Sociological Society, Atlanta, Georgia, April 2001.

Denemark, D. and C. Sharman. 1994. 'Political Efficacy, Involvement and Trust: Testing for Regional Political Culture in Australia.' Australian Journal of Political Science 29 (Special Issue): 81-102.

Fisher, S. 2000. 'Class Contextual Effects on the Conservative Vote in 1983.' British Journal of Political Science 30:347-60.

Holmes, J. and C. Sharman. 1977. The Australian Federal System. Sydney: Allen \& Unwin.

Johnston, R.J. 1987. 'The Geography of the Working Class and the Geography of the Labour Vote in England, 1983.’ Political Geography Quarterly 6:7-16.

Jones, K., R.J. Johnston and C.J. Pattie. 1992. 'People, Places and Regions: Exploring the Use of Multi-Level Modelling in the Analysis of Electoral Data.' British Journal of Political Science 22:343-80.

Kemp, D. 1978. Society and Electoral Behaviour in Australia. St Lucia: University of Queensland Press.

Leithner, C. 1997. 'Electoral Nationalisation, Dealignment and Realignment: Australia and the US, 1900-88.' Australian Journal of Political Science 32:205-22.

Long, J.S. 1997. Regression Models for Categorical and Limited Dependent Variables. Thousand Oaks, CA: Sage.

McAllister, I. 1987. 'Comment on Johnston.’ Political Geography Quarterly 6:45-50.

McAllister, I. 1997. 'Political Behaviour.' In Government, Politics, Power and Policy in Australia $6^{\text {th }}$ ed., eds A.Parkin, J. Summers and D. Woodward. Melbourne: Longman Cheshire.

McAllister, I. and D.T. Studlar. 1992. 'Region and Voting in Britain, 1979-87: Territorial Polarization or Artifact?’ American Journal of Political Science 36:16899.

Rasbash, J., W. Browne, H. Goldstein, Min Yang, I. Plewis, M. Healy, G. Woodhouse, D. Draper, I. Langford and T. Lewis 2000. A user's guide to MlwiN. London: Institute of Education, University of London.

Riker, W.H. 1964. Federalism: Origin, Operation, Significance. Boston: Little Brown. 
Charnock, David. (2003). Institutionally-induced pendulum? An assessment of state-level influences on postwar Australian federal voting, Australian Journal of Political Science, 38(1):119-132.

Sharman, C. 1994. 'Discipline and Disharmony: Party and the Operation of the Australian Federal System.' In Parties and Federalism in Australia and Canada, ed. C. Sharman. Canberra: Federalism Research Centre, The Australian National University.

Sharman, C. 1991. 'Forward to the Past: A Reply to Bean and Butler.' Australian Journal of Political Science 26:342-7.

Sharman, C. and A. Sayers. 1998. 'Swings and Roundabouts? Patterns of Voting for the Australian Labor Party at State and Commonwealth Lower House Elections, 1901-96.' Australian Journal of Political Science 33:329-44.

Snijders, Tom A.B. and R.J. Bosker. 1999. Multilevel Analysis: An Introduction to Basic and Advanced Multilevel Modeling. Thousand Oaks, CA: Sage. 
Charnock, David. (2003). Institutionally-induced pendulum? An assessment of state-level influences on postwar Australian federal voting, Australian Journal of Political Science, 38(1):119-132.

David Charnock is an Associate Professor in the School of Social Sciences at Curtin University.

My thanks to Kay Fisher and Peter Ellis for research assistance. The research was supported by Australian Research Council Large Grant number A79938063. Some of the work for this article was carried out while on visits to the University of North Carolina at Chapel Hill and the Australian National University and I would like to thank those institutions for their hospitality.

\section{Notes}

1. Aitkin $(1977,185)$ goes so far as to say that 'Inter-state variations are a minor puzzle.’

2. In a somewhat broader context, Riker (1964) argues for a crucial role for the party system in the general manner of operation of federalism. See Sharman (1994) for an exposition and an application to Australia.

3. On the other hand, conclusions from survey data are potentially subject to sampling errors, which is why the two types of analyses can complement each other.

4. The House representation entitlements of the states are essentially in proportion to their relative population sizes. In 1949 the states were entitled to the following numbers of seats in the House: NSW 47; Victoria 33; Queensland 18; South Australia 10; Western Australia 8; Tasmania 5. By 1998 (after the size of the House was increased between 1983 and 1984), the corresponding numbers were $50 ; 37 ; 27 ; 12 ; 14 ; 5$.

5. Leithner (1997) also analyses only ALP and Coalition voting; most earlier writers either did the same or analysed only two-party preferred votes. The multilevel modelling was carried out using the MlwiN computer program (Rasbash et al. 2000). 
Charnock, David. (2003). Institutionally-induced pendulum? An assessment of state-level influences on postwar Australian federal voting, Australian Journal of Political Science, 38(1):119-132.

6. Though many measures of explained variance in logistic regression models have been proposed, recent simulations reported in DeMaris (2001) suggest this (the McKelvey and Zavoina r-squared coefficient (e.g. Long (1997)) is the best one.

7. Since NSW is the most populous state, it has the largest sample sizes and hence makes the most reliable point of comparison.

8. As it turns out, this is the same as for the uncontrolled analyses.

9. Even if there were, in reality, no state effects among the electorate as a whole (after controlling for the impact of differing social and economic characteristics), the necessity for using random samples as the basis for drawing conclusions means that we would nevertheless expect to incorrectly find some apparently significant effects. When testing at a significance level of $5 \%$, if there actually were no state effects, we could still expect to incorrectly find 'significant' effects about $5 \%$ of the time i.e. about one time in 20. In this case, however, one in 20 of the 110 comparisons (five for each of the 22 elections) would be only five or six, and the 15 actually observed are considerably more than that.

10. The one to which I refer is that known as the power of a test. This refers to the probability that a given effect that does exist in the electorate as a whole will actually be detected when conclusions are based on only a random sample. Without going into excessive detail, one of the most important relevant considerations here is that having a larger sample in a state will make it more likely that an effect of any given size will be correctly detected. In our particular context, since the surveys were generally conducted with state samples roughly proportional to total state population sizes, this means that state effects that are present in the electorate as a whole are more likely to be correctly identified in the more populous states. 
Charnock, David. (2003). Institutionally-induced pendulum? An assessment of state-level influences on postwar Australian federal voting, Australian Journal of Political Science, 38(1):119-132.

11. As pointed out earlier, this is no more than the average of one in 20 that would incorrectly occur by chance if no voting differences were actually present between the NSW and Victorian electorates as a whole (after controlling for social and demographic aspects).

12. The results in Table 1 might also be seen as having some bearing on Hypothesis 1, since there is something of an imbalance between the first 11 elections (during 1946-72) and the second group of 11 elections (from 197498). Only five (of the 15) significant effects occur in the first half, and although the difference between the two periods is not quite statistically significant, one might tentatively suggest on this basis that there might have been a small degree of increased interstate variation since the early 1970s. Nevertheless, as already observed, the overall level remains very low.

13. There are a total of 70 tests (five in each of the 14 elections during the period), so one in 20 would be only three or four. The probability of finding eight or more significant state effects if none were actually present is less than 0.01 .

14. For example, see Bean and Butler (1991a, Table 1) for possible such interpretations for the 1990 election.

15. The 2001 Australian Election Study offers a suitable opportunity, since it did incorporate questions about feelings towards state premiers and opposition leaders. Bean (2002) finds mixed results but an indication that some state leaders influenced voting. 
Charnock, David. (2003). Institutionally-induced pendulum? An assessment of state-level influences on postwar Australian federal voting, Australian Journal of Political Science, 38(1):119-132.

TABLE 1: Significant state effects 1946-98, single-level models

\begin{tabular}{|c|c|c|c|c|c|}
\hline Election Year & Victoria & Queensland & S. Australia & W. Australia & Tasmania \\
\hline \multicolumn{6}{|l|}{1946} \\
\hline 1949 & & & & & $*(+)$ \\
\hline \multicolumn{6}{|l|}{1951} \\
\hline \multicolumn{6}{|l|}{1954} \\
\hline 1955 & & & $*(+)$ & & \\
\hline \multicolumn{6}{|l|}{1958} \\
\hline \multicolumn{6}{|l|}{1961} \\
\hline 1963 & & & $*(+)$ & & \\
\hline 1966 & & & & & $*(+)$ \\
\hline 1969 & & & $*(+)$ & & \\
\hline \multicolumn{6}{|l|}{1972} \\
\hline 1974 & $*(-)$ & & & & \\
\hline 1975 & & $*(-)$ & & & $*(-)$ \\
\hline \multicolumn{6}{|l|}{1977} \\
\hline 1980 & & $*(-)$ & & & \\
\hline 1983 & & $*(-)$ & & & $*(-)$ \\
\hline \multicolumn{6}{|l|}{1984} \\
\hline \multicolumn{6}{|l|}{1987} \\
\hline 1990 & & & & $*(-)$ & \\
\hline 1993 & & & & $*(-)$ & \\
\hline 1996 & & $*(-)$ & & & \\
\hline 1998 & & & & & $*(+)$ \\
\hline
\end{tabular}

Note: * indicates a state effect significantly different from that in NSW at the $5 \%$ significance level; the sign indicates whether the corresponding state effect increased (+) or decreased (-) the log-odds of voting for the ALP compared to NSW. The models used are single level logistic regressions for ALP voting, incorporating ALP and coalition voters. These models control for several important socio-demographic variables (age, occupational class, sex, economic position, religious denomination, urban-rural residence) in order to measure state effects net of variations in the social structures of the respective state electorates. 
Charnock, David. (2003). Institutionally-induced pendulum? An assessment of state-level influences on postwar Australian federal voting, Australian Journal of Political Science, 38(1):119-132.

TABLE 2: Significant state effects 1966-98, two-level models

\begin{tabular}{|c|c|c|c|c|c|}
\hline Election Year & Victoria & Queensland & S. Australia & W. Australia & Tasmania \\
\hline \multicolumn{6}{|l|}{1966} \\
\hline 1969 & & & $*(+)$ & & \\
\hline \multicolumn{6}{|l|}{1972} \\
\hline \multicolumn{6}{|l|}{1974} \\
\hline 1975 & & $*(-)$ & & & $*(-)$ \\
\hline \multicolumn{6}{|l|}{1977} \\
\hline \multicolumn{6}{|l|}{1980} \\
\hline 1983 & & $*(-)$ & & & $*(-)$ \\
\hline \multicolumn{6}{|l|}{1984} \\
\hline \multicolumn{6}{|l|}{1987} \\
\hline 1990 & & & & $*(-)$ & \\
\hline 1993 & & & & $*(-)$ & \\
\hline \multicolumn{6}{|l|}{1996} \\
\hline 1998 & & & & & $*(+)$ \\
\hline
\end{tabular}

Note: * indicates an individual-level state fixed effect significantly different from that in NSW at the5\% significance level; the sign indicates whether the corresponding state effect increased (+) or decreased (-) the log-odds of voting for the ALP compared to NSW. The models used are two-level random intercept logistic regressions for ALP voting, with level 2 being electoral divisions and level 1 individuals. ALP and coalition voters are included. These models control for several important socio-demographic variables (age, occupational class, sex, economic position, religious denomination, urban-rural residence) in order to measure state effects net of variations in the social structures of the respective state electorates. 
Charnock, David. (2003). Institutionally-induced pendulum? An assessment of state-level influences on postwar Australian federal voting, Australian Journal of Political Science, 38(1):119-132.

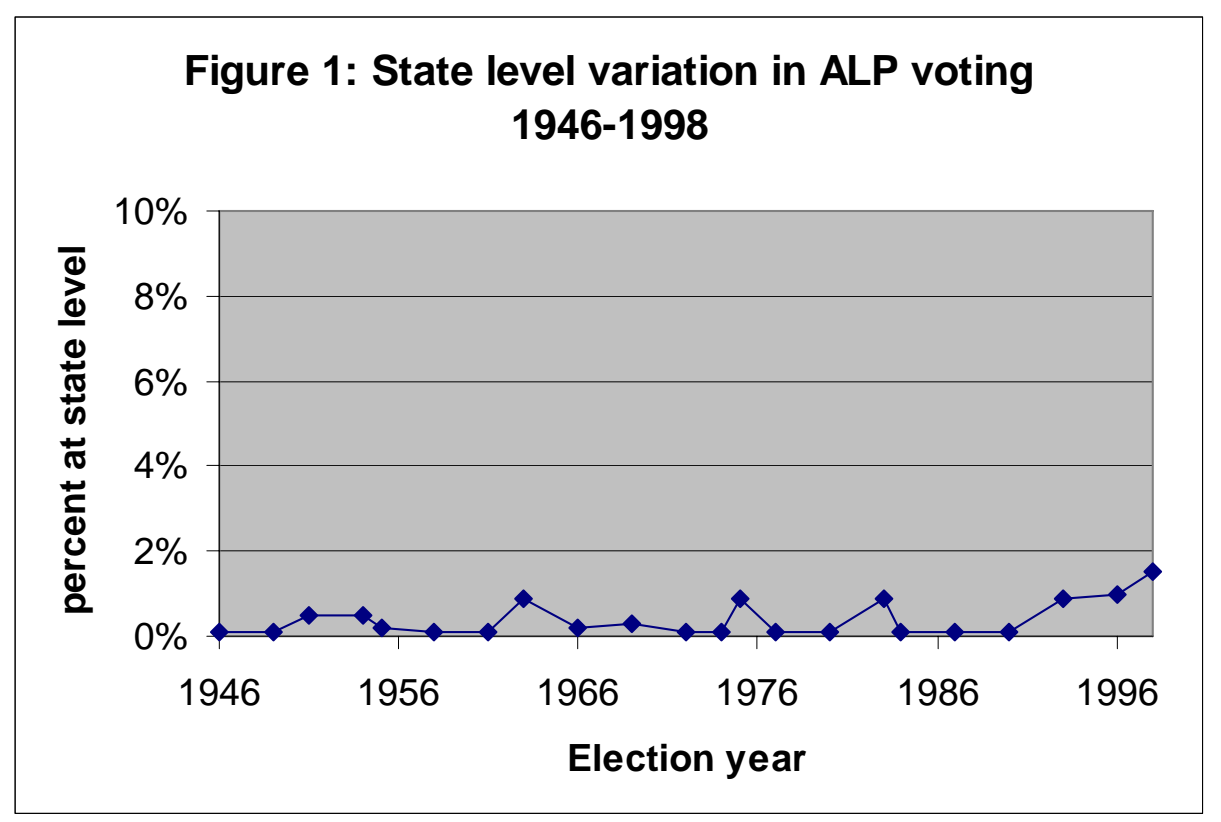

Note: quantities plotted are the percentages of total variance that are located at the state level in two level logistic regression null models for ALP voting, with individuals as level 1 and states as level 2. 
Charnock, David. (2003). Institutionally-induced pendulum? An assessment of state-level influences on postwar Australian federal voting, Australian Journal of Political Science, 38(1):119-132.

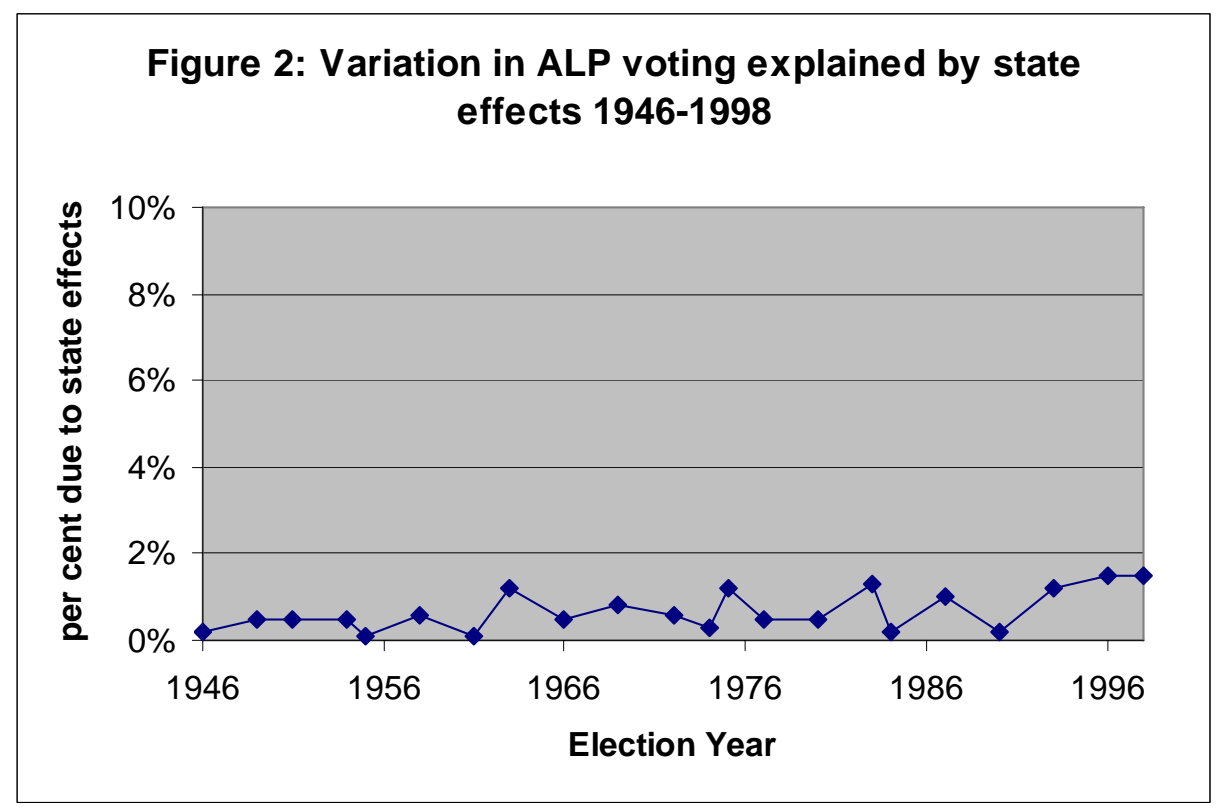

Note: quantities plotted here are the percentages of total variance explained by state fixed effects in single-level logistic regression models for ALP voting, where states are the only fixed effects included. 
Charnock, David. (2003). Institutionally-induced pendulum? An assessment of state-level influences on postwar Australian federal voting, Australian Journal of Political Science, 38(1):119-132.

****The versions of the Tables with gridlines included for printing****

TABLE 1: Significant state effects 1946-98, single-level models

\begin{tabular}{|c|c|c|c|c|c|}
\hline Election Year & Victoria & Queensland & S. Australia & W. Australia & Tasmania \\
\hline \multicolumn{6}{|l|}{1946} \\
\hline 1949 & & & & & $*(+)$ \\
\hline \multicolumn{6}{|l|}{1951} \\
\hline \multicolumn{6}{|l|}{1954} \\
\hline 1955 & & & $*(+)$ & & \\
\hline \multicolumn{6}{|l|}{1958} \\
\hline \multicolumn{6}{|l|}{1961} \\
\hline 1963 & & & $*(+)$ & & \\
\hline 1966 & & & & & $*(+)$ \\
\hline 1969 & & & $*(+)$ & & \\
\hline \multicolumn{6}{|l|}{1972} \\
\hline 1974 & $*(-)$ & & & & \\
\hline 1975 & & $*(-)$ & & & $*(-)$ \\
\hline \multicolumn{6}{|l|}{1977} \\
\hline 1980 & & $*(-)$ & & & \\
\hline 1983 & & $*(-)$ & & & $*(-)$ \\
\hline \multicolumn{6}{|l|}{1984} \\
\hline \multicolumn{6}{|l|}{1987} \\
\hline 1990 & & & & $*(-)$ & \\
\hline 1993 & & & & $*(-)$ & \\
\hline 1996 & & $*(-)$ & & & \\
\hline 1998 & & & & & $*(+)$ \\
\hline
\end{tabular}

Note: * indicates a state effect significantly different from that in NSW at the 5\% significance level; the sign indicates whether the corresponding state effect increased (+) or decreased (-) the log-odds of voting for the ALP compared to NSW. The models used are single level logistic regressions for ALP voting, incorporating ALP and coalition voters. These models control for several important socio-demographic variables (age, occupational class, sex, economic position, religious denomination, urban-rural residence) in order to measure state effects net of variations in the social structures of the respective state electorates. 
Charnock, David. (2003). Institutionally-induced pendulum? An assessment of state-level influences on postwar Australian federal voting, Australian Journal of Political Science, 38(1):119-132.

TABLE 2: Significant state effects 1966-98, two-level models

\begin{tabular}{|c|c|c|c|c|c|}
\hline Election Year & Victoria & Queensland & S. Australia & W. Australia & Tasmania \\
\hline 1966 & & & & & \\
\hline 1969 & & & $*(+)$ & & \\
\hline 1972 & & & & & \\
\hline 1974 & & & & & \\
\hline 1975 & & $*(-)$ & & & \\
\hline 1977 & & & & & \\
\hline 1980 & & & & & \\
\hline 1983 & & $*(-)$ & & & \\
\hline 1984 & & & & & \\
\hline 1987 & & & & & \\
\hline 1990 & & & & & \\
\hline 1993 & & & & & \\
\hline 1996 & & & & & \\
\hline 1998 & & & & & \\
\hline
\end{tabular}

Note: * indicates an individual-level state fixed effect significantly different from that in NSW at the5\% significance level; the sign indicates whether the corresponding state effect increased (+) or decreased (-) the log-odds of voting for the ALP compared to NSW. The models used are two-level random intercept logistic regressions for ALP voting, with level 2 being electoral divisions and level 1 individuals. ALP and coalition voters are included. These models control for several important socio-demographic variables (age, occupational class, sex, economic position, religious denomination, urban-rural residence) in order to measure state effects net of variations in the social structures of the respective state electorates. 